\title{
Treatment and long-term outcomes in pituitary carcinoma: a cohort study
}

\author{
Fernando Santos-Pinheiro' ${ }^{1}$, Marta Penas-Prado², Carlos Kamiya-Matsuoka², Steven G Waguespack ${ }^{3}$, \\ Anita Mahajan', Paul D Brown ${ }^{4}$, Komal B Shah ${ }^{5}$, Gregory N Fuller ${ }^{6}$ and Ian E McCutcheon?
}

${ }^{1}$ Department of Neurology, Medical College of Wisconsin, Milwaukee, Wisconsin, USA, ${ }^{2}$ Department of NeuroOncology, ${ }^{3}$ Department of Endocrinology, MD Anderson Cancer Center, Houston, Texas, USA, ${ }^{4}$ Department of Radiation Oncology, Mayo Clinic, Rochester, Minnesota, USA, ${ }^{5}$ Department of Radiology, ${ }^{6}$ Department of Pathology, and ${ }^{7}$ Department of Neurosurgery, MD Anderson Cancer Center, Houston, Texas, USA

Correspondence should be addressed to F Santos-Pinheiro Email

fsantos@mcw.edu

\begin{abstract}
Background: Pituitary carcinoma (PC) is an aggressive neuroendocrine tumor diagnosed when a pituitary adenoma (PA) becomes metastatic. PCs are typically resistant to therapy and develop multiple recurrences despite surgery, radiotherapy and chemotherapy. Recently, treatment with temozolomide (TMZ) has shown promising results, although the lack of prospective trials limits assessment of benefit.

Methods: We describe a single-center multidisciplinary experience in managing PC patients over a 22-year period and review previously published PC series.

Results: Seventeen patients were identified. Median age at PC diagnosis was 44 years (range 16-82 years), and the median time from PA to PC transformation was 5 years (range 1-29 years). Median follow-up time was 28 months. Most PCs were hormone-positive $(n=12)$ : ACTH $(n=5), \mathrm{PRL}(n=4)$, LH/FSH $(n=2)$ and GH $(n=1)$. All patients underwent at least one resection and at least one course of radiation after PC diagnosis. Immunohistochemistry showed high Ki-67 labeling index (>3\%) in 10/15 cases. Eight patients (47\%) had only central nervous system (CNS) metastases; six (35\%) had combined CNS and systemic metastases. The most commonly used chemotherapy was TMZ, and TMZbased therapy was associated with the longest PFS in 12 (71\%) cases, as well as the longest period from PC diagnosis to first progression (median 30 months). The 2, 3 and 5-year survival rate of the entire cohort was 71,59 and 35\%, respectively. All patients surviving $>5$ years had been treated with TMZ-based therapy. Conclusions: PC management benefits from multidisciplinary care and multimodality therapy. TMZ-based regimens were associated with high survival rates and long disease control.
\end{abstract}

\section{Introduction}

Pituitary carcinoma (PC) is a rare and aggressive neuroendocrine tumor (NET) accounting for approximately $0.1 \%$ of all pituitary neoplasms (1). The diagnosis is established after a pituitary adenoma (PA) becomes metastatic to the neuroaxis and/or outside the central nervous system (CNS) $(2,3,4)$. Little is known of the drivers for dissemination. Although p53 expression and Ki-67 labeling index correlate well with the degree of peritumoral invasion and aggressive behavior in PA, no specific histological or molecular markers are required to diagnose PC, according to the current World Health Organization (WHO) guidelines $(3,5)$. The management is challenging and a combination of surgical resection and/or radiation therapy is typically recommended, with chemotherapy often used when surgery and radiation are not possible or were previously unsuccessful.
(C) 2019 European Society of Endocrinology Printed in Great Britain
Published by Bioscientifica Ltd. 
Nevertheless, response to standard treatment is usually transient and PC recurrence is common (Figs $1 \mathrm{~A}$ and $1 \mathrm{~B}$ ), with a reported median overall survival (OS) of 1 year $(1,6)$. Improved outcome has been recently reported with the use of chemotherapy in recurrent tumors ( 1 , 7), especially temozolomide (TMZ) $(8,9,10,11,12,13$, $14,15,16,17,18)$ as a single agent, in combination with capecitabine (19) or concurrently with radiotherapy (20, $21)$. Recent practice guidelines for the management of aggressive pituitary tumors and PC have recommended temozolomide as first-line chemotherapy, as well as management by expert multidisciplinary teams (22). Here, we summarize a 22-year single-center experience treating newly diagnosed and recurrent PC, with an emphasis on multidisciplinary care and the use of TMZ-based therapy.

\section{Methods}

We conducted a retrospective review of all adult PC patients included in the University of Texas MD Anderson Cancer Center (MDACC) institutional databases from October 1, 1994 through January 31, 2017 under a protocol with waiver of consent approved by the University of Texas MD Anderson Cancer Center Institutional Review Board. All patients had undergone a biopsy or surgical resection of a pituitary mass and/or metastatic disease. Patients' demographic and clinical characteristics, treatments and outcome were reviewed. The diagnosis of PC was based on radiographic studies demonstrating metastatic dissemination and confirmed in equivocal cases by diagnostic biopsy or resection of a CNS or systemic lesion. Tumors were classified based on immunohistochemistry (IHC) findings and blood hormone levels (when available) (23). Since each PC patient received several lines of treatment (surgery, XRT, chemotherapy), we calculated the progressionfree survival (PFS) achieved by each treatment modality. PFS was defined as the presence of stable or decreased tumor burden in the primary sellar/locally invasive tumor and at all metastatic locations and was calculated from initiation of a given therapy to tumor progression. We then determined which treatment modality was associated with the longest PFS. We calculated OS from the initial diagnosis of PC to death or last follow-up. PC progression was defined based on radiographic evidence of new or interval growth of metastatic lesions or of the primary tumor itself, as reported in the patient's records. Tumor size was determined by bidimensional measurements as per standard institutional practice (i.e., sum of the products of the two longest diameters in the perpendicular dimensions of all tumors), but specific measurements were not always available in the chart and cannot be provided given the retrospective nature of this series. Death was confirmed by review of medical records and/or death certificate.

\section{Results}

\section{Demographics}

A total of 17 patients with PC were seen over the study period. Their clinical, treatment and outcome

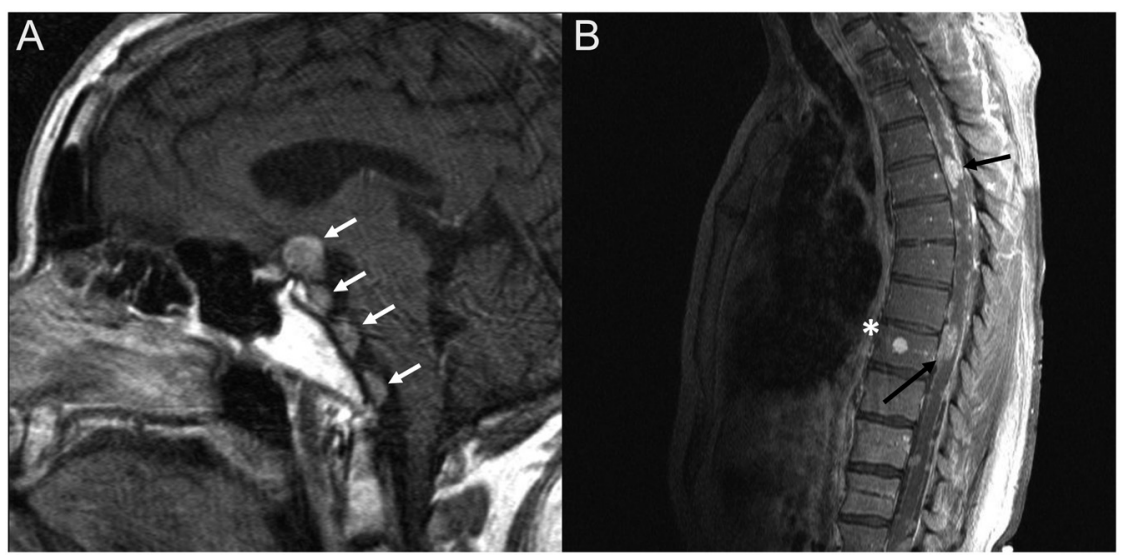

Figure 1

(A) A 17-year-old girl with aggressive pituitary tumor, previously treated with surgery and radiation, presented with Cushing syndrome. Sagittal T1 post contrast image shows multiple dural based metastases (white arrows), leading to diagnosis of PC. (B) 48-year-old man with surgically proven dural based metastases from pituitary carcinoma was treated with multiple surgeries, radiation and chemotherapy. He presented with foot drop. Sagittal T1 post contrast fat-saturated image shows presumed bone metastasis $\left(^{*}\right)$ and innumerable intrathecal metastases (black arrows). 
旁|

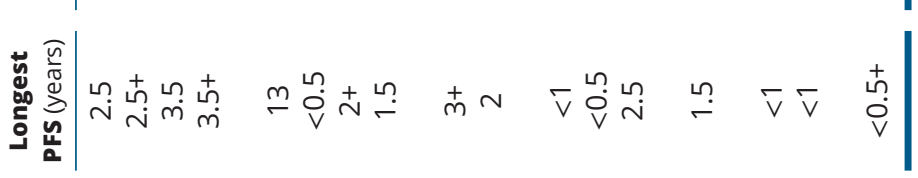

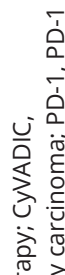

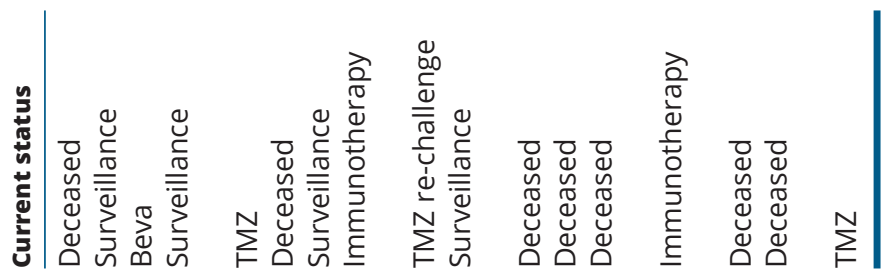

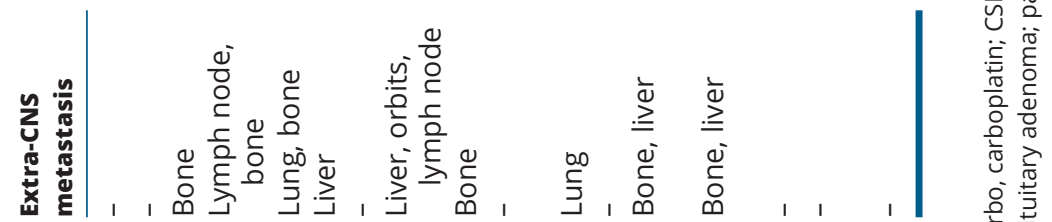

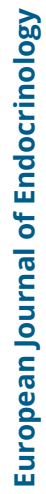

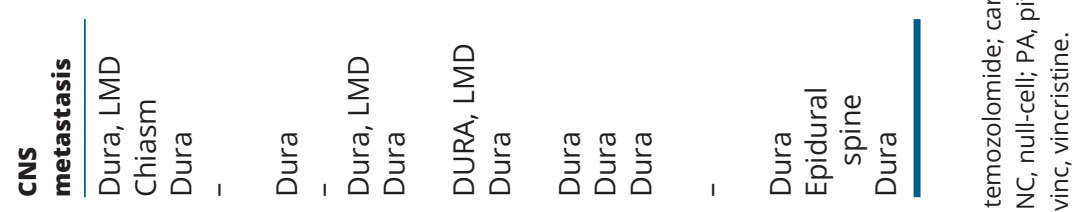

步

竞苛

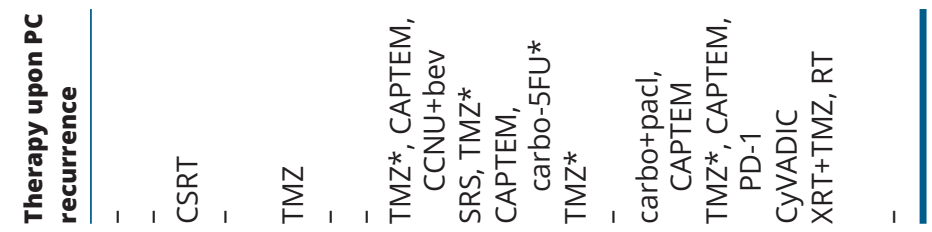

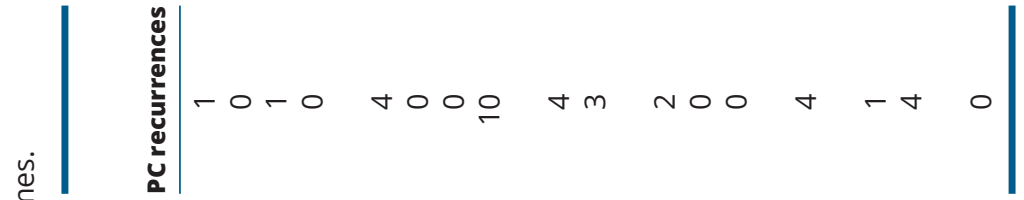

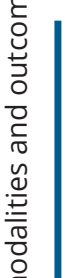

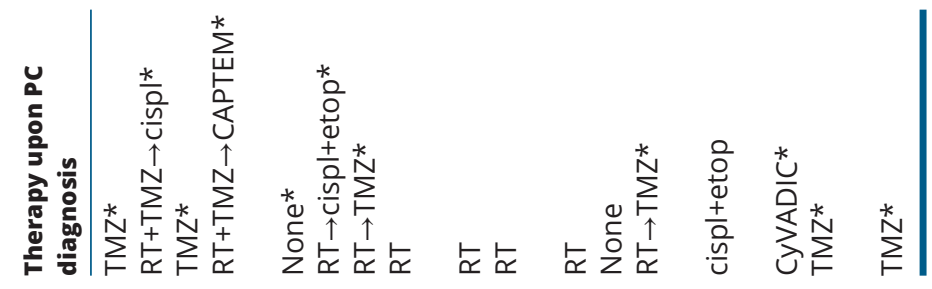

ن.

ơ

这语

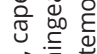

$\sum_{\dot{H}} \varepsilon_{0}^{\infty} \sum_{i}^{N}$

这苝

它完离

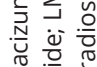

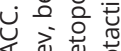

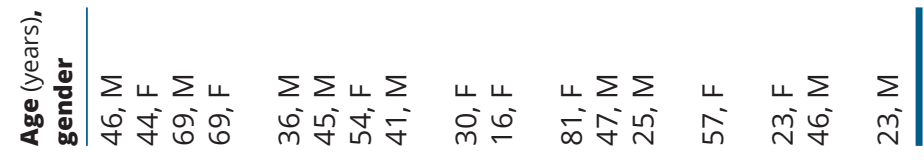

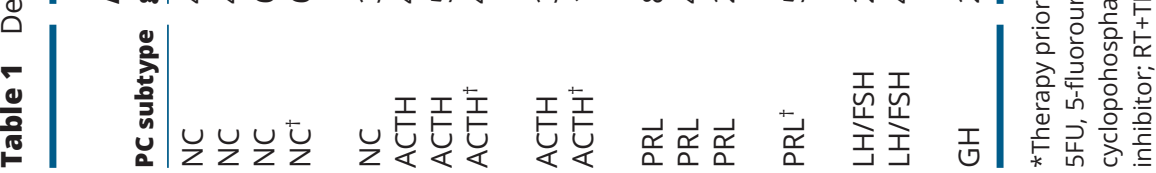


data are summarized in Table 1 . There was no gender preponderance (male:female $=9: 8$ ). The median age at diagnosis of PC was 44 years (range 16-82 years). Thirteen patients with PC were diagnosed and treated at MDACC, while four had the PC diagnosis confirmed in our institution but were treated elsewhere. Of note, three of the study subjects have already been presented in previous publications $(21,24)$.

\section{PA to PC time to transformation, PC subtype and clinical findings}

The median PA to PC time to transformation was 5.5 years (range 2-29 years, Table 1). One patient (NC-PC) was diagnosed simultaneously with PA and metastatic disease (de novo PC) and was excluded from the calculation of median time to transformation. Tumors were classified into somatotroph (GH-PC), lactotroph (PRL-PC), corticotroph (ACTH-PC), gonadotroph (LH/FSH-PC) and null-cell (NC-PC). IHC was not available in two cases, which were therefore classified based on blood hormone levels (1 PRL-PC and 1 GH-PC); there were no cases of TSH-PC, plurihormonal or double tumors. The majority of PC $(n=12)$ were hormone positive: ACTH-PC $(n=5)$, PRL-PC $(n=4)$, LH/FSH-PC $(n=2)$ and GH-PC $(n=1)$. Five patients had NC-PC. Among the IHC hormone-positive subtypes, ACTH-PC had the longest median TTT time to transformation (5 years, range 2-29), followed by PRL-PC (4 years, range 2-12 years), LH/FSH-PC (3 years, range 2-4 years) and GH-PC (2 years). The median time to transformation of NC-PC was 10 years (range 8-15 years).

All patients were symptomatic at the time of diagnosis of PC and clinical presentation most commonly involved neurological symptoms such as headaches $(n=9$ (53\%)) and visual impairment $(n=5 \quad(30 \%))$. Other symptoms such as facial pain, focal weakness, increased thirst and weight gain were also reported.

The one patient with GH-PC had clinical signs of acromegaly. Three out of the five patients with ACTH-PC had history of Cushing syndrome diagnosed prior to PC diagnosis and required adrenalectomy during their disease to control symptoms; the other two patients had silent tumors, neither of which became secreting.

\section{Tumor location (local invasion and metastatic sites)}

Prior to PC diagnosis, 15 out of 17 pituitary tumors were locally invasive (one case had no information available about tumor extension prior to PC diagnosis; one case was diagnosed simultaneously with a PA and a distant CNS lesion). The most common site of local invasion was the cavernous sinus $(n=8,47 \%)$ and sphenoid sinus ( $n=8,47 \%)$. Involvement of optic structures (optic nerves, orbit, chiasm) was observed in $35 \%$ of the patients $(n=6)$, resulting in visual loss in three cases. Most patients $(n=13)$ developed CNS metastases (dural based, $n=13$; leptomeningeal, $n=3$ ). In eight patients ( $47 \%$ of the entire cohort) metastases were documented only in the CNS, although the systemic work-up was not homogeneously performed. Six (35\%) patients had concomitant CNS and extra-CNS metastases (bone, $n=3$; lymph nodes, $n=1$; other organ (liver, lung), $n=2$ ), with two of them having more than one location of extra-CNS metastases. Three (17\%) patients had extra-CNS metastases without any metastases within the CNS (Table 1).

\section{PC histopathological findings and molecular characterization}

Either before or after PC diagnosis was suspected based on imaging findings of metastatic lesions, all patients underwent at least one surgical resection of the pituitary tumor (mean of 2.3, range 1-6). IHC studies (15 sellar tumor samples available) showed a median Ki-67 labeling index of 11\% (range 1-40\%); high Ki-67 labeling index $(>3 \%)$ was present in most, but not all, sellar tumor samples (10/15, 67\%). The highest median Ki-67 index was found in NC and PRL subtypes, while the lowest median Ki-67 index was found on FSH/LH subtype: NC ( $n=5$, median $24 \%$, range $2-38 \%) ;$ ACTH $(n=5$, median 2\%, range 1-40\%); PRL $(n=4,16$ and 25\%; Ki-67 was not tested in two cases); FSH/LH ( $n=2,7$ and 1\%); GH $(n=1$, $10 \%)$. Mutant p53 was positive in only 1 (NC-PC) out of the 12 tumor samples tested. The p53 mutation was tested negative via NGS in four samples, while IHC staining was used in the other 8 samples, based on a p53 cutoff of $80 \%$ of nuclear staining (Supplementary Table 1, see section on supplementary data given at the end of this article). Assessment for MGMT expression via IHC was done in only two patients (both negative: NC-PC, $n=1$; PRL-PC, $n=1$ ) as this was not a routine test recommended for this population.

Molecular studies via PCR-based next generation sequencing (NGS) of tumor samples (primary and/or metastatic site) was done in four patients. Mutational analyses were performed using two different high depth targeted sequencing platforms consisting of Oncomine ${ }^{\circledR}$ (201 genes) and FoundationOne ${ }^{\circledR}$ (315 genes) panels to identify actionable DNA alterations in tumor samples (25, 
26). Further details on the gene panels used in each case are available in Supplementary Table 1. A hypermutator phenotype was present in three of them $(\mathrm{ACTH}-\mathrm{PC}=2$; NC-PC $=1$ ). In one ACTH-PC patient, an initial 46-gene panel was negative, but when a 400-gene panel was used, 20 potentially actionable gene mutations were identified (ATM, GNAS, APC, CCNE1, CSF1R, EML4, ERBB3, ERBB4, FBXW7, FGFR4, IL7R, JAK1, MLL, MLL2, MLL3, NF2, NTRK3, PDGFRB, PTPN11, TOP1) along with 53 other gene mutations identified in a tumor sample from tumor extension into the orbit. The other ACTH-PC patient had one potentially actionable mutation (CREBBP splice site 2086_2113+49del77) along with other 20 gene variations of unknown significance identified in progressive sellar tumor. In the NC-PC patient, a metastatic tumor sample tested positive for MSH6 and negative for MGMT by IHC. Among the two patients without hypermutator phenotype, a PRL-PC had no mutations identified in 147 genes tested in a metastatic tumor sample, while a NC-PC patient had a primary tumor sample positive for FGFR1 amplification (Supplementary Table 1).

\section{Treatment modalities and outcome}

Most patients received multimodality therapy, and management was discussed in multidisciplinary conference with participants from Endocrinology, Neurosurgery, Neuroradiology, Radiation Oncology and Neuro-Oncology.

\section{Surgery}

The average number of pituitary resections from the initial PA diagnosis was 1.8 per patient (range 1-3). Seven patients $(41 \%)$ required a craniotomy for further resection after an initial transsphenoidal sub-total resection of PA. The most common surgical techniques for resection of pituitary tumor were endonasal transsphenoidal approach $(n=14)$ (including one endoscopic approach), followed by pterional craniotomy $(n=10)$ and sublabial transsphenoidal approach $(n=2)$. Other surgical approaches consisted of transfacial/ lateral rhinotomy and fronto-orbito-zygomatic craniotomy (one case each). Complications related to surgery occurred only in two patients and consisted of a cerebrospinal fluid leak and need for repositioning of a ventriculoperitoneal shunt. Of note, three ACTH-PC patients underwent bilateral adrenalectomy prior to PC diagnosis to control refractory Cushing's disease.

\section{Radiation therapy}

Following PC diagnosis, 7 (41\%) patients were treated with radiotherapy to the sella $(n=5)$ or radiotherapy concurrent with TMZ $(n=2)$. Intensity-modulated radiation therapy (IMRT, total dose: 45-54 Gy, divided in 25-30 fractions) was the most common radiotherapy modality in this setting. With regards to metastatic disease, a total of 13 foci were treated with radiotherapy (CNS metastases: $n=7$; extra-CNS metastases: $n=6$ ). IMRT was the most frequent technique $(n=10)$, followed by stereotactic radiosurgery (SRS, $n=4$ ), craniospinal radiation (CSRT, $n=2$, both in the setting of leptomeningeal carcinomatosis) and intensitymodulated proton therapy (IMPT, $n=1$ ).

\section{Chemotherapy}

TMZ was the most frequently prescribed chemotherapy in this series (Table 1), and it was used in all PC subtypes: $\mathrm{NC}=5 / 5 ; \mathrm{ACTH}=4 / 5 ; \mathrm{PRL}=3 / 4 ; \mathrm{LH} / \mathrm{FSH}=1 / 2 ; \mathrm{GH}=1 / 1$. TMZ was used for newly diagnosed PC as monotherapy $(n=4)$, concurrently with radiotherapy $(n=2)$ and immediately following radiotherapy $(n=2)$. The most common TMZ scheduling and dosage was $150 \mathrm{mg} / \mathrm{m}^{2}$ for 5 days on a 28-day cycle, for 12 months $(n=6)$. TMZ was also used for recurrent PC in seven patients, given as monotherapy $(n=5)$, combined with capecitabine $(n=2$; CAPTEM: capecitabine $1500 \mathrm{mg} / \mathrm{m}^{2}$ in divided doses twice daily, days 1 to 14 , and TMZ $100 \mathrm{mg} / \mathrm{m}^{2}$, days 1 to 14 of a 28-day cycle, for a total of six cycles) (11) or concurrently with radiotherapy $\left(n=1\right.$; TMZ $75 \mathrm{mg} / \mathrm{m}^{2}$ daily for 42 days combined with radiation 5 days a week for 6 weeks). Four patients (one LH/FSH-PC, one ACTH-PC and two PRL-PC) were re-challenged with a TMZ-based therapy upon PC recurrence. One of them (LH/FSH-PC) was treated with TMZ upon PC diagnosis and had recurrence less than a year later; this patient then received concurrent TMZ and radiotherapy and died less than 1 year later (OS 5 years). The other three patients were treated with TMZbased therapy upon first and subsequent PC recurrences; all of them were initially treated with TMZ alone (which conferred a median PFS of 1.5 years, range $1-2.5$ years) and were then treated with CAPTEM, which provided PFS of less than 1 year.

TMZ therapy was overall well tolerated with anticipated side effects, and in none of the patients was the therapy terminated or delayed due to hematological or non-hematological adverse events. The most common adverse events attributed to TMZ were fatigue and nausea 
(35\%), with no reported grade 3-5 toxicity, according to CTCAE v4.0 (2009).

Other chemotherapy regimens used for newly diagnosed PC were cisplatin (after concurrent radiation and TMZ, $n=1)$, cisplatin plus etoposide $(n=1)$ and cyplophosphamide in combination with vincristine, doxorubicin and dacarbazine (CyVADIC, $n=1$ ). In the recurrent setting, treatments included bevacizumab as a single agent $(n=3)$, bevacizumab plus irinotecan $(n=1)$, bevacizumab plus pan-FGFR kinase inhibitor $(n=1$, as part of a phase 1 clinical trial), bevacizumab plus lomustine $(n=1)$, carboplatin plus vincristine $(n=1)$ and carboplatin plus 5-FU $(n=1)(24)$.

In this series, three patients were enrolled in three different phase 1 clinical trials testing: (1) tipifarnib plus sorafenib, a farnesyltransferase inhibitor and a multi-tyrosine kinase inhibitor (VEGFR, PDGFR, Raf), respectively; (2) pembrolizumab, a PD-1 inhibitor, and (3) BGJ398, a pan-FGFR inhibitor. The outcome of these patients treated with experimental drugs is not discussed here.

\section{Outcome}

The median follow-up after PC diagnosis was 2 years (range 1-13 years). Progression after any given therapy, that is, after first treatment for newly diagnosed PC and after any treatment for subsequent progression, if applicable, occurred in 10 (59\%) patients, at a median time of 18 months (range 0.33-13 years) and at a median occurrence of 1 (range 1-10 occurrences) per patient. Of the seven patients without progression during follow-up, four were diagnosed with PC less than 3.5 years prior to the end of the study and were still alive, and three patients were deceased in less than 1 year from PC diagnosis. The cause of death was unknown, but death due to progression of PC could not be excluded. There were no operative deaths. Median time from PC diagnosis to first PC recurrence was 9 months (range 3->42 months). Eight patients (47\%) were treated with upfront TMZ or TMZ-based therapy and achieved a median time from PC diagnosis to first PC recurrence of 30 months (range 5->42 months). Another eight patients $(47 \%)$ were treated with upfront chemoor radiotherapy without $\mathrm{TMZ}$ and achieved a median time from PC diagnosis to first PC recurrence of 10 months (range 0.33-13 years). Interestingly, one patient (NC-PC, initial metastatic site: cerebellum) achieved 13 years of stable disease without upfront therapy and is now on TMZ following the fourth recurrence of disease (further metastatic sites: pons, lung and bone). Overall,
TMZ-based therapy was associated with the longest PFS in $12(71 \%)$ patients when used at diagnosis or recurrence (median 21 months, range $4->42$ months). The $2-, 3$ - and 5 -year survival rates for the entire cohort were $71(n=12)$, $59(n=10)$ and $35 \%(n=6)$, respectively. Of the patients who were alive at least 5 years from diagnosis, 2 patients (one NC-PC, one ACTH-PC, both still alive) survived more than 10 years and all five had received treatment with TMZ-based therapy (Table 1 ). One refractory case is currently under treatment with the PD-1 inhibitor pembrolizumab as part of a phase 1 clinical trial. Eighty percent of NC-PC were alive at last follow-up, in contrast with 58\% of IHC hormone-positive PC. There were seven reported deaths by the end of the study period. Cause of death was infectious etiology in one patient (pneumonia, while off temozolomide for 1 month) and unknown in six patients (largely because of loss of follow-up).

\section{Discussion}

PC is a rare and aggressive form of pituitary tumor for which limited therapeutic guidelines exist and limited treatment and outcome data have been published. As no curative treatment has been established for PC to date, this case series aimed to present our multidisciplinary experience with the use of multiple modalities of treatment over a prolonged period of follow-up at a single institution. Although limited by its retrospective nature, our experience suggests that a multimodality approach involving a combination of surgical resection, radiotherapy and chemotherapy (particularly TMZ-based when used upfront) correlates with better outcome, even in the context of multiple tumor progressions (2-year OS rate: $71 \%$, 3-year OS rate: 59\%, 5-year OS rate: $35 \%$ ), compared with previous reports in the literature (Table 2) $(1,6,21,27)$.

According to the current WHO classification of pituitary tumors (2017) (4), the presence of metastatic disease in the CNS or systemically suffices to designate a pituitary tumor as PC. However, this definition disregards intrinsic histopathologic or molecular features of the pituitary tumor linked to malignant behavior (largely unknown at present) and relies exclusively on the detection of metastasis.

The strategic location of the pituitary in relation to other intracranial structures (internal carotid artery, dura, cavernous sinus) may facilitate the hematogenous, CSF and lymphatic spread of cancerous cells into the neuraxis and extra-CNS locations. Yet, metastatic disease occurs in 
Table 2 Previously published pituitary carcinoma case series by single and multicenter groups.

\begin{tabular}{|c|c|c|c|c|c|c|c|c|}
\hline Studies & Study period & $\begin{array}{l}\text { Single } \\
\text { center }\end{array}$ & $\begin{array}{c}\text { PC } \\
\text { cases }\end{array}$ & PC type & $\begin{array}{l}\text { TMZ } \\
\text { Tx }\end{array}$ & Other Tx modalities & PFS* (months) & OS* (months) \\
\hline$(27)$ & 1955-1994 & Yes & 15 & $\begin{array}{l}\mathrm{ACTH}(7), \operatorname{PRL}(7), \\
\mathrm{NC}(1)\end{array}$ & 0 & $\begin{array}{l}\text { Surgery, RT, cytotoxic } \\
\text { agents }\end{array}$ & Not reported & $\begin{array}{l}\text { 1-year OS 66\%, } \\
\text { mOS } 22\end{array}$ \\
\hline (44) & 1970-1997 & Yes & 4 & ACTH(1), PRL(3) & 0 & Cytotoxic agents, RT & 11.5 & 11.5 \\
\hline$(45)$ & 1983-2013 & Yes & 2 & $\operatorname{PRL}(2)$ & & Cytotoxic agents & 9 & 10 \\
\hline (46) & Not reported & No & 5 & ACTH(2), PRL(3) & 5 & Surgery, RT & Not reported & Not reported \\
\hline (29) & 2006-2011 & No & 12 & $\begin{array}{r}\text { ACTH(3), PRL(3), } \\
\text { NC(4), NOS(2) }\end{array}$ & 10 & Not reported & Not reported & Not reported \\
\hline$(47)$ & $1973-2008$ & No & 7 & Not reported & 0 & Surgery & Not reported & $\begin{array}{c}\text { 1-year OS 57.1\%, } \\
\text { 2-year OS } 28.6 \% \\
\text { 5-year OS } 28.5 \%\end{array}$ \\
\hline (18) & Not reported & No & 8 & $\begin{array}{l}\text { ACTH(3), PRL(2), } \\
\text { GH(3) }\end{array}$ & 8 & $\begin{array}{l}\text { Surgery, RT, cytotoxic } \\
\text { agents }\end{array}$ & Not reported & Not reported \\
\hline$(48)$ & 2006-2015 & Yes & 2 & $\mathrm{ACTH}(1), \mathrm{GH}(1)$ & 0 & Surgery, RT & $\begin{array}{l}156(\mathrm{ACTH}) \\
22(\mathrm{GH})\end{array}$ & $\begin{array}{l}178(\mathrm{ACTH}) \\
34(\mathrm{GH})\end{array}$ \\
\hline (49) & 2018 & Yes & 2 & $\mathrm{ACTH}(2)$ & 2 & Surgery, RT & 6 & $12+$ \\
\hline$(43)$ & 2016-2018 & No & 40 & $\begin{array}{c}\mathrm{ACTH}(19), \mathrm{PRL}(15), \\
\mathrm{GH}(1), \mathrm{FSH} / \\
\mathrm{LH}(2), \mathrm{NC}(3)\end{array}$ & 40 & $\begin{array}{l}\text { Surgery, RT, } \\
\text { bevacizumab }\end{array}$ & Not reported & Not reported \\
\hline $\begin{array}{r}\text { Present } \\
\text { study }\end{array}$ & 1994-2017 & Yes & 17 & $\begin{array}{c}\mathrm{ACTH}(5), \mathrm{PRL}(4) \\
\mathrm{GH}(1), \mathrm{FSH} / \\
\mathrm{LH}(2), \mathrm{NC}(5)\end{array}$ & 15 & Surgery, RT & 18 & $\begin{array}{l}\text { mOS 36; 2-year OS } \\
65 \%, 3 \text {-year OS } \\
53 \%, 5 \text {-year OS } \\
29 \%\end{array}$ \\
\hline
\end{tabular}

*Median PFS and OS since PC diagnosis.

$\mathrm{ACTH}$, adrenocorticotrophic hormone; FSH/LH, follicle-stimulating hormone/luteinizing hormone; GH, growth hormone; NC, null-cell; NOS, not otherwise specified; OS, overall survival; PC, pituitary carcinoma; PFS, progression-free survival; PRL, prolactin hormone; RT, radiotherapy; TMZ, temozolomide.

only $0.1-0.2 \%$ of all PA cases and little is known of the biologic drivers for malignant behavior in these tumors (7). Most patients in our series had CNS metastasis with involvement of the meninges $(n=11)$, but extra-CNS metastases involving vertebral bodies, long bones, liver, lung and lymph nodes were seen in over half the patients, suggesting that the mechanism of spread of PC may include both dissemination via CSF and/or hematogenous spread, given its close proximity to vascular structures as well as the meninges lining the sella.

The spectrum between PA and PC likely implies biologic differences beyond the presence of metastases, although these are unknown at present. Interestingly, we observed in our series a time of transformation from a PA to PC varying widely from a few years to more than two decades, highlighting potential heterogeneity of factors driving malignant transformation. Among the IHC hormone-positive PC subtypes, GH- and LH/FSH-PC had the shortest latency period, while PRL-PC, ACTH-PC and NC-PC had the longest latency. However, given the small number of patients with each subtype, we cannot determine with certainty if this holds true in the entire population of patients with PC and other molecular factors independent from hormonal expression may play a more important role.
The 2017 WHO classification does not recommend a specific Ki-67 and mitotic index cutoff for definition of PC. In our series, the median Ki-67 index was 11\%, but varied between 1 and 40\%, and a Ki-67 labeling index >3\% was present in most, but not all cases; therefore, a low Ki-67 does not eliminate the risk of malignant transformation. The median Ki-67 index seemed to differ depending on the hormonal subtype (higher in NC and PRL subtypes), but the small number of cases in each subtype precludes definitive conclusions. In clinical practice, despite the lack of official cut-offs, presence of high Ki-67 and mitotic index is commonly incorporated in decisions about frequency of surveillance and in discussions with patients about the potential risk for recurrence.

Other pathologic biomarkers such as mutant p53 expression, MGMT IHC or promoter methylation status, MSH6 IHC and mutation profile were not systematically tested in our series (Supplementary Table 1), although they may be of clinical relevance for prediction of treatment response (i.e., alkylating agents), prognostication and/or stratification in clinical trials $(28,29,30)$.

Our series provides ample data on patterns of use of temozolomide and outcome in patients with PC in clinical practice. The rationale for the use of TMZ in this disease is supported by several clinical and pharmacological 
studies in neuroendocrine and primary brain tumors, indicating its excellent blood-brain barrier penetration, in addition to its homogenous distribution in CNS and extra-CNS tissues $(12,31)$. Ramanathan et al. reported an objective response rate of $34 \%$ in a Phase II study using dacarbazine (DTIC) intravenously as single-agent therapy for metastatic pancreatic neuroendocrine tumors (PNETs) (32). TMZ, which is bioactivated into the same metabolite as DTIC (5-methyltriazenoimidazole-4-carboxamide, MTIC), has the advantage of undergoing spontaneous decarboxylation (and therefore bypassing hepatic activation) (33). The relatively mild toxicity profile and ease of use (oral formulation) are also advantages of TMZ over other chemotherapies. TMZ works by inducing cell apoptosis or cell senescence in rapidly dividing cells and it is non-specific to any mitosis phase. Furthermore, TMZ demonstrated good response in primary brain tumors and previously untreated brain metastases when added to radiotherapy (34). In parallel, the relatively low MGMT expression seen in NET, including PA and PC, increases their sensitivity to alkylating agents such as $\operatorname{TMZ}(35,36)$. The 2017 European guideline for pituitary tumors encourages testing of MGMT expression by IHC on aggressive pituitary tumors and PC (even though only a minority of them exhibit homogenous MGMT expression), as it may help predict treatment success with temozolomide, the first-line chemotherapy recommended for such tumors $(22,37)$. Nevertheless, MGMT may not be the sole driver for response to TMZ, and other enzymes, such as MSH6, may also contribute to PC sensitivity to alkylating agents (28). For this reason, caution is warranted to use MGMT expression as the only criteria to decide on the use of temozolomide in PC and locally aggressive PA, as both lack of response in patients with low expression and favorable response in patients with high expression has been described (38). Therefore, a trial of therapy with TMZ may be warranted regardless of MGMT status, particularly if other treatment options have been exhausted.

Further reports described the effective use of TMZ combined with capecitabine in recurrent and metastatic PNETs $(11,12,21,39,40,41)$. The addition of capecitabine to TMZ (CAPTEM) is based on the theory that sequential pretreatment with capecitabine may potentiate the cytotoxicity of $\mathrm{TMZ}$ by synergistically depleting thymidine, leading to apoptosis $(11,31)$. A recent randomized Phase II study has shown improved PFS and OS of capecitabine in combination with TMZ compared to TMZ alone in advanced pancreatic NETs (42); however, this has not been tested in PCs and whether CAPTEM is superior to TMZ alone in this patient population remains unknown. Potential benefits of using combined therapy must be carefully weighed against the potential for added toxicities. In our series, the use of CAPTEM therapy in patients with previous progression after TMZ monotherapy was limited to three cases, and definitive conclusions about the benefit of CAPTEM in the setting of TMZ failure cannot be reached.

In our patient cohort, we observed a longer median time between PC diagnosis and first PC recurrence in patients treated with upfront TMZ-based therapy (30 months) compared with patients treated with other lines of upfront therapy that was not TMZ-based (10 months), although the low number of patients and the potential bias inherent in retrospective series limits generalization of the validity of these results. Our results are also superior to those previously reported in the literature (Table 2); this includes results from a contemporary study in which TMZ was commonly prescribed, and which reported that $42.5 \%$ of PC patients were deceased with median follow-up of 12 months (43). Nevertheless, we are unable to confirm whether the favorable outcome seen with TMZ is due to 'first therapy effect', when the longest PFS is usually seen, whether it is related to higher TMZ efficacy or, more likely, whether it is a combination of both.

Radiotherapy with concurrent TMZ was completed in three patients, which was then followed by cisplatin $(n=1)$, TMZ $(n=1)$ and capecitabine plus TMZ $(n=1)$. Two of these patients had disease control for more than 2 years, and all three patients survived for at least 3 years. This is in agreement with a recent European survey and a review article which showed that concurrent TMZ and RT was associated with increased response rate compared to TMZ alone $(7,43)$. The longer survival rates in our cohort may be correlated to the multimodality approach and/or TMZ use, especially considering that all long-term ( $>5$ years) survivors were treated with TMZ-based therapy.

This study has the limitations typical of an observational retrospective study, including the small number of patients and single-center setting. Therefore, we are unable to draw any comparative statistical analysis among the different treatment modalities given to each PC patient or across PC patients. Furthermore, a tertiary institution serving as a national and international referral center invariably has a selection bias for patients with more severe conditions and poorer prognosis. Finally, the confounding bias related to several lines of therapy in a relatively short timeframe also limits the interpretation of a true cause-effect phenomenon between each line 
of therapy and the observed outcome. Despite all these limitations, our series provides valuable information on the demographics, tumor characteristics, multidisciplinary management, treatment modalities and outcome of patients with this rare malignancy for which prospective data are lacking to guide estimation of prognosis and decisions on therapy.

\section{Conclusion}

PC is a rare and aggressive neuroendocrine malignancy. Factors leading to malignization of PAs are largely unknown and warrant further study. Local recurrence is frequent, and metastases occur in both CNS as well as extra-CNS locations. Multidisciplinary approach is critical for management of this tumor. A combination of surgical resection, radiotherapy and chemotherapy (particularly TMZ-based) may result in prolonged survival. In this case series, which is the largest single-institution experience published in the literature, early use of chemotherapy, specifically TMZ, combined with standard PC management (surgical resection and radiotherapy) was well tolerated and associated with improved survival rates compared to the previous literature.

\section{Supplementary data}

This is linked to the online version of the paper at https://doi.org/10.1530/ EJE-18-0795.

\section{Declaration of interest}

The authors warrant that the work intended for publication is original and has not been published other than as an abstract in any language or format and has not been submitted elsewhere for print or electronic publication consideration. They further warrant that the work does not contain any material that is defamatory or the publication of which would violate any copyright or other personal, intellectual, property, contract, or proprietary right of any person or entity. None of the authors declare any funding or disclosures.

This article was prepared while M Penas-Prado was employed at the UT MD Anderson Cancer Center. The opinions expressed in this article are the author's own and do not reflect the view of the National Institutes of Health, the Department of Health and Human Services, or the United States government.

\section{Funding}

This research did not receive any specific funding from any funding agency in the public, commercial or not-for-profit sector.

\section{Author contribution statement}

M Penas-Prado and C Kamiya-Matsuoka: both authors contributed equally.

\section{References}

1 Heaney AP. Clinical review: pituitary carcinoma: difficult diagnosis and treatment. Journal of Clinical Endocrinology and Metabolism 2011 96 3649-3660. (https://doi.org/10.1210/jc.2011-2031)

2 Doniach I. Pituitary carcinoma. Clinical Endocrinology 199237 194-195. (https://doi.org/10.1111/j.1365-2265.1992.tb02307.x) 3 Scheithauer BW, Kovacs KT, Laws Jr ER \& Randall RV. Pathology of invasive pituitary tumors with special reference to functional classification. Journal of Neurosurgery 198665 733-744. (https://doi. org/10.3171/jns.1986.65.6.0733)

4 Lopes MBS. The 2017 World Health Organization classification of tumors of the pituitary gland: a summary. Acta Neuropathologica 2017 134 521-535. (https://doi.org/10.1007/s00401-017-1769-8)

5 Mete O, Ezzat S \& Asa SL. Biomarkers of aggressive pituitary adenomas. Journal of Molecular Endocrinology 201249 R69-R78. (https://doi.org/10.1530/JME-12-0113)

6 Kaltsas GA, Nomikos P, Kontogeorgos G, Buchfelder M \& Grossman AB. Clinical review: diagnosis and management of pituitary carcinomas. Journal of Clinical Endocrinology and Metabolism 200590 3089-3099. (https://doi.org/10.1210/jc.2004-2231)

7 Dworakowska D \& Grossman AB. Aggressive and malignant pituitary tumours: state-of-the-art. Endocrine-Related Cancer 201825 R559-R575. (https://doi.org/10.1530/ERC-18-0228)

8 Morokuma H, Ando T, Hayashida T, Horie I, Inoshita N, Murata F, Ueki I, Nakamura K, Imaizumi M, Usa T et al. A case of nonfunctioning pituitary carcinoma that responded to temozolomide treatment. Case Reports in Endocrinology 20122012 645914. (https://doi.org/10.1155/2012/645914)

9 Losa M, Bogazzi F, Cannavo S, Ceccato F, Curto L, De Marinis L, Iacovazzo D, Lombardi G, Mantovani G, Mazza E et al. Temozolomide therapy in patients with aggressive pituitary adenomas or carcinomas. Journal of Neuro-Oncology $2016 \mathbf{1 2 6}$ 519-525. (https://doi.org/10.1007/s11060-015-1991-y)

10 Fadul CE, Kominsky AL, Meyer LP, Kingman LS, Kinlaw WB, Rhodes CH, Eskey CJ \& Simmons NE. Long-term response of pituitary carcinoma to temozolomide. Report of two cases. Journal of Neurosurgery 2006105 621-626. (https://doi.org/10.3171/ jns.2006.105.4.621)

11 Thearle MS, Freda PU, Bruce JN, Isaacson SR, Lee Y \& Fine RL. Temozolomide (Temodar $(\mathrm{R}))$ and capecitabine $(\mathrm{Xeloda}(\mathrm{R}))$ treatment of an aggressive corticotroph pituitary tumor. Pituitary $2011 \mathbf{1 4}$ 418-424. (https://doi.org/10.1007/s11102-009-0211-1)

12 Fine RL, Gulati AP, Krantz BA, Moss RA, Schreibman S, Tsushima DA, Mowatt KB, Dinnen RD, Mao Y, Stevens PD et al. Capecitabine and temozolomide (CAPTEM) for metastatic, well-differentiated neuroendocrine cancers: the Pancreas Center at Columbia University experience. Cancer Chemotherapy and Pharmacology 201371 663-670. (https://doi.org/10.1007/s00280-012-2055-z)

13 Lim S, Shahinian H, Maya MM, Yong W \& Heaney AP. Temozolomide: a novel treatment for pituitary carcinoma. Lancet: Oncology 20067 518-520. (https://doi.org/10.1016/S14702045(06)70728-8)

14 Campdera M, Palacios N, Aller J, Magallon R, Martin P, Saucedo G, Lilienfeld H \& Estrada J. Temozolomide for aggressive ACTH pituitary tumors: failure of a second course of treatment. Pituitary 201619 158-166. (https://doi.org/10.1007/s11102-015-0694-x)

15 Ceccato F, Lombardi G, Manara R, Emanuelli E, Denaro L, Milanese L, Gardiman MP, Bertorelle R, Scanarini M, D'Avella D et al. Temozolomide and pasireotide treatment for aggressive pituitary adenoma: expertise at a tertiary care center. Journal of Neuro-Oncology 2015122 189-196. (https://doi.org/10.1007/s11060-014-1702-0)

16 Strowd RE, Salvatori R \& Laterra JJ. Temozolomide retreatment in a recurrent prolactin-secreting pituitary adenoma: hormonal and radiographic response. Journal of Oncology Pharmacy Practice 201622 517-522. (https://doi.org/10.1177/1078155215569556) 
17 Bruno OD, Juarez-Allen L, Christiansen SB \& Danilowicz K. Longlasting complete remission after therapy with temozolomide in two patients with macrocorticotropinoma causing Cushing's disease. Clinical Endocrinology 201583 143-145. (https://doi.org/10.1111/ cen.12727)

18 Bengtsson D, Schroder HD, Andersen M, Maiter D, Berinder K, Feldt Rasmussen U, Rasmussen ÅK, Johannsson G, Hoybye C, van der Lely AJ et al. Long-term outcome and MGMT as a predictive marker in 24 patients with atypical pituitary adenomas and pituitary carcinomas given treatment with temozolomide. Journal of Clinical Endocrinology and Metabolism 2015100 1689-1698. (https://doi. org/10.1210/jc.2014-4350)

19 Gulati AP, Krantz B, Moss RA, Moyal WN, Tsushima DA, Mowatt KB, Schreibman S \& Fine RL. Treatment of multiple endocrine neoplasia 1/2 tumors: case report and review of the literature. Oncology $2013 \mathbf{8 4}$ 127-134. (https://doi.org/10.1159/000342961)

20 Zhong C, Yin S, Zhou P \& Jiang S. Pituitary atypical adenoma or carcinoma sensitive to temozolomide combined with radiation therapy: a case report of early identification and management. Turkish Neurosurgery 201424 963-966. (https://doi.org/10.5137/10195149.JTN.9629-13.1)

21 Kamiya-Matsuoka C, Cachia D, Waguespack SG, Crane CH, Mahajan A, Brown PD, Nam JY, McCutcheon IE \& Penas-Prado M. Radiotherapy with concurrent temozolomide for the management of extraneural metastases in pituitary carcinoma. Pituitary 201619 415-421. (https://doi.org/10.1007/s11102-016-0721-6)

22 Raverot G, Burman P, McCormack A, Heaney A, Petersenn S, Popovic V, Trouillas J, Dekkers OM \& European Society of Endocrinology. European Society of Endocrinology Clinical Practice Guidelines for the management of aggressive pituitary tumours and carcinomas. European Journal of Endocrinology 2018178 G1-G24. (https://doi.org/10.1530/EJE-17-0796)

23 Lloyd RV, Osamura RY, Klöppel G \& Rosai J. Pathology and genetics of tumours of endocrine organs. In IARC WHO Classification of Tumours, 2017.

24 AbdelBaki MS, Waguespack SG, Salceda V, Jones J, Stapleton SL, Baskin DS \& Okcu MF. Significant response of pituitary carcinoma to carboplatin, leucovorin and fluorouracil chemotherapy: a pediatric case report and review of the literature. Journal of Neuro-Oncology 2017135 213-215. (https://doi.org/10.1007/s11060-017-2554-1)

25 Chen K, Meric-Bernstam F, Zhao H, Zhang Q, Ezzeddine N, Tang LY, Qi Y, Mao Y, Chen T, Chong Z et al. Clinical actionability enhanced through deep targeted sequencing of solid tumors. Clinical Chemistry 201561 544-553. (https://doi.org/10.1373/clinchem.2014.231100)

$26 \mathrm{https} / / / \mathrm{www}$.foundationmedicineasia.com/content/dam/foundationmedicine/en_US/assets/pdf/FOne_Current_Gene_List.pdf.

27 Pernicone PJ, Scheithauer BW, Sebo TJ, Kovacs KT, Horvath E, Young WF, Lloyd RV, Davis DH, Guthrie BL \& Schoene WC. Pituitary carcinoma: a clinicopathologic study of 15 cases. Cancer 199779 804-812. (https://doi.org/10.1002/(sici)1097. 0142(19970215)79:4<804::aid-cncr18>3.0.co;2-3)

28 Matsuno A, Murakami M, Hoya K, Yamada SM, Miyamoto S, Yamada S, Son JH, Nishido H, Ide F, Nagashima H et al. Molecular status of pituitary carcinoma and atypical adenoma that contributes the effectiveness of temozolomide. Medical Molecular Morphology 201447 1-7. (https://doi.org/10.1007/s00795-013-0050-z)

29 Hirohata T, Asano K, Ogawa Y, Takano S, Amano K, Isozaki O, Iwai Y, Sakata K, Fukuhara N, Nishioka H et al. DNA mismatch repair protein (MSH6) correlated with the responses of atypical pituitary adenomas and pituitary carcinomas to temozolomide: the national cooperative study by the Japan Society for Hypothalamic and Pituitary Tumors. Journal of Clinical Endocrinology and Metabolism 201398 1130-1136. (https://doi.org/10.1210/jc.2012-2924)

30 Lau Q, Scheithauer B, Kovacs K, Horvath E, Syro LV \& Lloyd R. MGMT immunoexpression in aggressive pituitary adenoma and carcinoma. Pituitary 201013 367-379. (https://doi.org/10.1007/ s11102-010-0249-0)

31 Zacharia BE, Gulati AP, Bruce JN, Carminucci AS, Wardlaw SL, Siegelin M, Remotti H, Lignelli A \& Fine RL. High response rates and prolonged survival in patients with corticotroph pituitary tumors and refractory Cushing disease from capecitabine and temozolomide (CAPTEM): a case series. Neurosurgery 201474 E447-E455; discussion E455. (https://doi.org/10.1227/NEU.0000000000000251)

32 Ramanathan RK, Cnaan A, Hahn RG, Carbone PP \& Haller DG. Phase II trial of dacarbazine (DTIC) in advanced pancreatic islet cell carcinoma. Study of the Eastern Cooperative Oncology Group-E6282. Annals of Oncology 200112 1139-1143. (https://doi. org/10.1023/a:1011632713360)

33 Carmen Avendano JCM. DNA alkylating agents. In Medicinal Chemistry of Anticancer Drugs, pp 139-176. Ed JCM Carmen Avendano. Elsevier, 2008.

34 Antonadou D, Paraskevaidis M, Sarris G, Coliarakis N, Economou I, Karageorgis P \& Throuvalas N. Phase II randomized trial of temozolomide and concurrent radiotherapy in patients with brain metastases. Journal of Clinical Oncology 200220 3644-3650. (https:// doi.org/10.1200/JCO.2002.04.140)

35 Kulke MH, Hornick JL, Frauenhoffer C, Hooshmand S, Ryan DP, Enzinger PC, Meyerhardt JA, Clark JW, Stuart K, Fuchs CS et al. O6-methylguanine DNA methyltransferase deficiency and response to temozolomide-based therapy in patients with neuroendocrine tumors. Clinical Cancer Research 200915 338-345. (https://doi. org/10.1158/1078-0432.CCR-08-1476)

36 Salehi F, Scheithauer BW, Kovacs K, Horvath E, Syro LV, Sharma S, Manoranjan B \& Cusimano M. O-6-methylguanine-DNA methyltransferase (MGMT) immunohistochemical expression in pituitary corticotroph adenomas. Neurosurgery 2012 70 491-496; discussion 496. (https://doi.org/10.1227/ NEU.0b013e318230ac63)

37 Salehi F, Scheithauer BW, Kros JM, Lau Q, Fealey M, Erickson D, Kovacs K, Horvath E \& Lloyd RV. MGMT promoter methylation and immunoexpression in aggressive pituitary adenomas and carcinomas. Journal of Neuro-Oncology 2011104 647-657. (https:// doi.org/10.1007/s11060-011-0532-6)

38 Ortiz LD, Syro LV, Scheithauer BW, Rotondo F, Uribe H, Fadul CE, Horvath $\mathrm{E} \&$ Kovacs K. Temozolomide in aggressive pituitary adenomas and carcinomas. Clinics 201267 (Supplement 1) 119-123. (https://doi.org/10.6061/clinics/2012(sup01)20)

39 Devata S \& Kim EJ. Neoadjuvant chemotherapy with capecitabine and temozolomide for unresectable pancreatic neuroendocrine tumor. Case Reports in Oncology 20125 622-626. (https://doi. org/10.1159/000345369)

40 Saranga-Perry V, Morse B, Centeno B, Kvols L \& Strosberg J. Treatment of metastatic neuroendocrine tumors of the thymus with capecitabine and temozolomide: a case series. Neuroendocrinology 201397 318-321. (https://doi.org/10.1159/000345938)

41 Crespo G, Jimenez-Fonseca P, Custodio A, Lopez C, CarmonaBayonas A, Alonso V, Navarro M, Aller J, Sevilla I, Grande E et al. Capecitabine and temozolomide in grade $1 / 2$ neuroendocrine tumors: a Spanish multicenter experience. Future Oncology 201713 615-624. (https://doi.org/10.2217/fon-2016-0434)

42 Kunz PL, Catalano PJ, Nimeiri H, Fisher GA, Longacre TA, Suarez CJ, Yao JC, Kulke MH, Hendifar AE, Shanks JC et al. A randomized study of temozolomide or temozolomide and capecitabine in patients with advanced pancreatic neuroendocrine tumors: a trial of the ECOG-ACRIN Cancer Research Group (E2211). Journal of Clinical Oncology 201836 (Supplement) 4004. (https://doi.org/10.1200/ JCO.2018.36.15_suppl.4004)

43 McCormack A, Dekkers OM, Petersenn S, Popovic V, Trouillas J, Raverot G, Burman P \& ESE Survey Collaborators. Treatment of aggressive pituitary tumours and carcinomas: results of a European 
Society of Endocrinology (ESE) survey 2016. European Journal of Endocrinology 2018178 265-276. (https://doi.org/10.1530/EJE-170933)

44 Kaltsas GA, Mukherjee JJ, Plowman PN, Monson JP, Grossman AB \& Besser GM. The role of cytotoxic chemotherapy in the management of aggressive and malignant pituitary tumors. Journal of Clinical Endocrinology and Metabolism 199883 4233-4238. (https://doi. org/10.1210/jcem.83.12.5300)

45 Roncaroli F, Nose V, Scheithauer BW, Kovacs K, Horvath E, Young WF, Lloyd RV, Bishop MC, Hsi B \& Fletcher JA. Gonadotropic pituitary carcinoma: HER-2/neu expression and gene amplification. Report of two cases. Journal of Neurosurgery 200399 402-408. (https://doi.org/10.3171/jns.2003.99.2.0402)

46 Raverot G, Sturm N, de Fraipont F, Muller M, Salenave S, Caron P, Chabre O, Chanson P, Cortet-Rudelli C, Assaker R et al. Temozolomide treatment in aggressive pituitary tumors and pituitary carcinomas: a French multicenter experience. Journal of Clinical Endocrinology and Metabolism 201095 4592-4599. (https://doi. org/10.1210/jc.2010-0644)

47 Hansen TM, Batra S, Lim M, Gallia GL, Burger PC, Salvatori R, Wand G, Quinones-Hinojosa A, Kleinberg L \& Redmond KJ. Invasive adenoma and pituitary carcinoma: a SEER database analysis. Neurosurgical Review 201437 279-285; discussion 285-276. (https:// doi.org/10.1007/s10143-014-0525-y)

48 Wang YQ, Fan T, Zhao XG, Liang C, Qi XL \& Li JY. Pituitary carcinoma with intraspinal metastasis: report of two cases and review of the literature. International Journal of Clinical and Experimental Pathology 20158 9712-9717.

49 Yoo F, Kuan EC, Heaney AP, Bergsneider M \& Wang MB. Corticotrophic pituitary carcinoma with cervical metastases: case series and literature review. Pituitary 201821 290-301. (https://doi. org/10.1007/s11102-018-0872-8)

Received 1 October 2018

Revised version received 20 July 2019

Accepted 26 July 2019 